\title{
Photography, Literature, and Writing: An Interdisciplinary Approach for the Representation of the Truth and the Reality
}

\author{
Md. Raihan-Bin-Shafiq
}

\author{
Lecturer, Department of English, Bangladesh Army University of Science and Technology (BAUST)
} Emailid: raihan026@gmail.com

\begin{abstract}
The verisimilitude of truth of photography has placed it as an unequalled medium representing and expressing the reality. Yet, its widespread use as an art, the selection and exclusion of certain subjects that may be related to the ideology held by the photographer problematize such assertion. This essay will critically engage, through a few examples, with this difficulty in twentieth century's context. The problem of photographic representation, say of poverty, or war or labour exploitation will be addressed as in many cases they end up becoming fashionable clichés. While so doing, the essay will show how the use of literary narrative and photographic representation together may address the problem, and that may again confront difficulties in an age ubiquity ofimages.
\end{abstract}

Keywords- Photography, literature, art, documentary, narrative, abstraction.

Photography as a medium of art is generally viewed to have the capacity and scope to hold and represent the truth than other forms of art such as writing and painting,. Yet, it is a big question whether photography as a medium could reach beyond the realm of art; as long as it is a form of art there is an inevitable gap between what the art exhibit and the reality. Sontag (1978) argues that just as in Plato's allegory of the cave where the subjects can only behold the image of the truth, photography can only represent the image of the truth and not the truth. She also goes further to state that photography 'is the opposite of understanding' (Sontag 1978). This problem may be perceived by viewing photography as a commodity.

Sontag (1978) also states, "To photograph people is to violate them...It turns people into objects that can be symbolically possessed." Photography, as a commodity, in many cases indiscriminately turns its subjects into a beautiful work of art to look upon, no matter if it is of a beautiful garden, or of war or the struggle of working class. In place of enabling the viewers to perceive the extent of beauty or suffering or horror of its subject, many photographs, representing poverty, terror, war, famine and overall human suffering, end up only to be appraised for their aesthetic representation of the subjects. This may result in a sort of inertia of understanding and does not necessarily urge for a change in the status quo. So, photography, when used as a commodity, reduces the revolutionary impetus of its own representation. Benjamin (1970) urges, 'What we should demand from photography is the capacity of giving a print a caption which would tear it away from fashionable clichés and give it a revolutionary use value'. Benjamin (1970) insists a kind of literary-photographic practise that will supersede the photography from its 'fashionable clichés'. Thus he urges for a change of techniques in representing the subjects from both the authors' and the photographers' end. As Hess (2018) expounds, "In order for the photograph to become progressive, Benjamin suggests that it break down the barrier between writing and image". In this regard Brecht also echoes Benjamin's assertion, "Only that which narrates can make us understand (as cited in Sontag, 1978, p 19)." How Brecht put this in practice will be discussed later in this essay. For the time being it is suffice to say that a union between photography and literature has been used by Brecht and many other twentieth century photographers to resolve the problems of the gap between art and reality, or art and understanding. Artists and authors, in the mode of production, who side with the working class and want to represent their struggle through their work can convey their message, according to Benjamin, by using literature to photography and thereby changing techniques and blurring the boundary between the authors and the artists.

Now that, what is at stake here is the inherent problem of photographic representation, which may elevate poverty to the work of art- a beautiful object to look upon-a commodification of art. The problem could be perceived by realizing what hollows Dadaism, a radical practices of modern art, off its radical impulse as Benjamin (1970) puts it:

The bourgeois apparatus of production and publication can assimilate an astonishing number of 
revolutionary themes, and can even propagate them without seriously placing its own existence of the class that poses them into question.(p4)'

Benjamin (1970) discusses how Dadais $m$ and other modern revolutionary art forms were helplessly caught up in the bourgeoisie production mode. The evil lies in two historical conditions; one, the mode of aesthetic representation, what Benjamin (1970) terms a 'new objectivity,' reduces human suffering to the status of art; two, the bourgeois apparatus of production already appropriated many such revolutionary practices as it did Dadaism. Now, to effectively address and confront these difficulties, he wants the intellectuals and artists to position themselves in the production process to express solidarity with the proletarians, rather than placing them as their ideological patrons (Benjamin, 1970). What Benjamin urges through photographic practise with the aid of narration, and of literature is to return the meaning to life hollowed by capitalis m. In short, Benjamin (1970) insists authors take up photography and photographers adopt writing as an interdisciplinary approach amalgamating image and te xts, transforming photography to something else and something more.

However, propping up photography with writing again suggests the inadequacy of photography to hold and exhibit the truth alone. Also, the above discussion urges to examine how the insertion of text or caption may equip photography an extra narrative power, so that it may be provided with a revolutionary use value, as Benjamin (1970) urges. This leads to ask some further questions such as, how to rescue photography as an art caught up in the bourgeoisie mode of production. Or, in what ways Benjamin's assertion may keep the photographic representation, say of poverty, from being a mere consumer goods in an age of ubiquity and prevalence of capital, goods and images over human life? Further, how effectively Benjamin's advocated literary-photographic practice may convey the understanding of reality and truth and make this medium work towards emancipation of human being from the capitalistic servitude? These are some of the historically determined difficulties of the twentieth century in complicity with the aesthetic practise of the period posing difficulty to Benjamin's assertion. Now, the form of difficulty and a way out may be examined by looking at a few notable literary-photographic representations of $20^{\text {th }}$ century.

To this end, Evans and Agee's (1960) textual and photographic narrative titled Let us Now Praise Famous Men (1960), of the poverty of the Alabama cotton farmers and their families during the great depression in the 1930's the USA, may postulate a significant understanding of literary-photographic representation. Their documentary narrative along with a melancholic tone in the writing does not represent the impoverished living conditions of the farmers and their families as something deplorable. Rather, a commendable effort to dignify their poverty and the farmers' and their families' implicit pride is visible throughout the photographic and textual narrative of the work. Nonetheless, signs of improvisations and process of an artistic selection of inclusion/exclusion, and an aesthetic representation of poverty is evident in most of the images-evinced through the image of the kitchen utensils arranged in a neat and beautiful manner, or in the group photos of the children and the women, or in the bold and sturdy facial expression of a middle aged farm man to give a few examples (Evans and Agee, 1960). Looking at the photos and reading the text, one may feel sad and indulge into melancholy, but they do not urge for a change. As Rule(2001) observes, "Evans's photography of sawmill circles on the floor or the picking-bag's drag along the cotton row, ennobles them; that it beautifies, almost beatifies, the bemused children of poverty more than any adjective or adverb Agee might edit out of his copy." In other words Walker's photography sublimates the ordinariness of life and its poverty and hence does what he does not intend to: turn it a work of art (Evans and Agee, 1960, p7). Thus, at the end their aestheticized work cannot help getting commodified- a carefully selected number of photographs to be looked upon and appraised as work of art.

. Noticeable, irrespective of their dignify ing of the subjects and condemnation to artistic representation of the poverty as commodity, the elevation of poverty is also somewhat helplessly entangled into the aesthetic credo of an unwritten prohibition on the representation of the real condition of labour and production as formulated by Gautier in the first half of the $19^{\text {th }}$ centuryi . Moreover, dignifying poverty through using aesthetic techniques of images is expressive of the contentment of the represented subjects - the poor farmer and their families and, hence does not call for a necessity to change their conditions. Nonetheless, this artistic selection suggests that certain aspects of Evans' photographs could not really break through the 'fashionable clichés' of photography as pointed out by Benjamin, irrespective of his and Agee's condemnation of such practise. Now that, in the first half of the twentieth century people still believed in the authentic representation of the documentary photography. Agee (1960) believes camera as 'the central instrument' of his time and outrages at its widespread misuse while being emphatic on it's 'immediacy'. Accordingly, in the book he puts his prose as complementary to the sense of immed iacy to Walker's documentary photographs representing the life of the farmers. Their effort to prevent their representation as art 
evident in the documentary style is a testimony of their vow to represent reality as it is; however, the artistic techniques -improvisation, inclusion/exclusion and so onsuggests the opposite. Now it might be asserted that, although the powerful and strong literary texts of the book intends to work as complementary to their photographic allies, the photographs in the book prevent to do so.

Still, the incapacity to reproduce reality and being confined within the realm of art turns the photographers, as other artists, aloof from their subjects and their social reality shaped by the bourgeoisie mode of production. Following Benjamin's (1970) assertion, it is understood that the gap between the artist and the world could not be bridged by photography alone unless the artists and authors turn it into something else and something more. Thus, I would argue, as I mentioned earlier through Walker Evans example, that it is inadequate to simply point out the limitations of the artists as trapped in a bourgeois apparatus of production and publication. This is a gap produced in complicity both by an aesthetic practise of art and the division of labour inherent in capitalism.

Now that, the confinement of the photography to aesthetic representation and its inadequacy as a medium to represent reality have turned useful for Brecht in his photo-book The War Primer (1998). This photo-book is a collection of a host of images of the Second World War collected by Brecht from Life magazine and some other unknown sources. This singular fact regard ing the sources is that Brecht pastes many of them while leaving the places and dates unknown to the views which deprive the photos of their indexical quality. So, it shows Brecht's unwillingness to make it a documentary work which is evident in the absence of any indexical caption below the photographs. Instead, Brecht surrogates the space for captions with poetic epigrams. The epigrams do not work in a complementary way with the photographs to produce any emission of reality from the photographs. Rather, the use of poetry in lieu of prose is significant to critical understanding in this regard. Proses in general tends to fit well with facts and reality than poetry does; in the captions of journalistic and documentary photographs the use of poems is hardly seen. Thus, Brecht's use of poetic epigrams as captions is self-evident: he does not want to turn his photographic book as WWII photo-documentary. On the contrary, he denounces the photographic ability to represent reality, yet he turns this limitation to work for his own revolutionary message to convey through the aid of poetry. However, this denouncement of photographic capacity to represent reality through lack of context and sources and absence of prose and facts is understood better through Brecht's own thoughts concerning the is sue of the representation and the perception of reality. In absence of perceiving reality as a whole what he asserts is:

And so what we actually need is to "construct something', something 'artificial' "posed." What we therefore equally need is art. But the old concept of art based on experience is invalid. For whoever reproduces those aspects of reality that can be experienced does not reproduce reality. For some time reality has no longer been experienceable as a totality (cited in Long, 2008, p7).

Now, what he implies here is not an artistic representation of reality in fragmentation as seen in the artistic practice of Surrealis $m$ and Dadais m. Looking at the photographs with the epigrams, one may perceive that he puts into practise what Benjamin insists the authors to do, to transform the photography to something else. By and large, he inserts the poetic device upon the photographs to 'construct something' as he states above, and manipulates the art of poetry ('an art not based on experience' and opposed to the 'photographic 'truth',), and simultaneously deploys an artistic process of selecting the photographs. By so doing, he strips off the sort of artistic photography that is caught into the practise of fashionable cliché which reduces every person and event as beautiful photographic objects to look at. Also, by decontextualizing the images through the absence of conventional caption and lack of source in many cases, he breaks out of the illusion of the photography's sense of immediacy. At the same time, he presents his viewers and readers with the author's ability to impart the images with new meanings and contexts through literary device; he thoroughly exhausts the photographic narrative through his poetry. This is what Benjamin (1970) demands from the authors, "the literarization of life" (p5).

Putting literary device, Brecht imparts new meaning to the world and humanity by redeploying photography with the aid of literature. His craftsmanship lies in the fact that he does it all by not putting the poetry as complementary to the image, rather by positioning the image and texts antagonistically to impart meaning and context. In a way this is an attempt to show the readers-viewers the clandestine meaning of the life and world that is lost in a world of false propaganda. As Scranton (2017) comments, "It is War Primer's existence as an artifact...that gives it an almost magical power to bring to life the truth of a world sunk in the shadows of myth". Scranton (2017) analyses and shows how Brecht's representation bring to the fore the real truth of WWII as a war driven by greed and fear where "the vampiric rich fed on the machine-gunned and fire-bombed poor" (Scranton, 2017) in contrast to the popular belief that it is a war for the good against the evil. For instance, in image 
number 7 , there are the fierce sea waves, some rough rocks captured in the sea of Skagerrek where the German's loss was given to 3500 (Brecht, 1998). Now, as it is clearly seen and a fact that both the image and the description is incapable to represent the horror and reality of the war, Brecht's poem has unfailingly given it a new reality in place of a reality lost forever at the bottom of the ocean, encrypted beneath the image, . He puts his epigram, "Fisherman, when fish have filled your net/Remember us, and let just one swim free (Brecht, 1998)." These lines have a tragic intonation, bringing back the voices of the lives lost forever at the bottom of the sea, and voices through the metaphor of the fish and fisherman want to be remembered. Their yearning to the fisherman to let one fish alive talks about life against death, and life's melancholic yearning to see other lives thrive and, read contemplatively, the words hold and provoke something strong and powerful than many horrify ing images of war could. The metaphor of the fish and the fisherman ultimately evokes the life of servitude under the fascist or the bourgeoisie regime that contextualise the war as the triumph of the greedy and money mongers and ultimately the defeat of ordinary people. Even the allies win the war, the life of servitude of many of the subjects do not suffice.

However, Brecht's effort to put new context and meaning of life lost in the war may be suggestive of some lost reality of the capitalist society that photography, as a commodity, does not produce. This revelation of photography and finding meanings hidden behind it refers to the deceiving nature of commodity and exchange value as an attempt to hide the real production relation as Bajorek (2011) comments on Brecht's War Primer(1998):

This book aims to teach the art of reading images...The great importance about social relations, which capitalism painstakingly and brutally maintains, turns the thousands of photos in the illustrated magazines into the hieroglyphic tablets, indecipherable to the unsuspecting readers (p125).

Yet, this deciphering of the true social relations beneath the hieroglyph of images, as a true revolutionary literary-photographic practise, faces strong challenge in the age of ubiquity of images - when the social reality is constantly shaped and reshaped by images that Debord (2009) terms as Society of the Spectacle. Because, when reality is shaped by images there is no hidden reality to decipher. Baudrillard (2015) asserts the predominance of image over reality that he terms as simulacra which poses challenges to such literary-photographic practise that tries to unearth the reality, the real social relations. Moreover, a society saturated by images also and only doubly reaffirms the lack of the indexical quality of photographic representation to hold the truth, and that again suggest the influence of image over life and reality that hollow out any meaning of them. For Baudrillard (2015), the loss of any meaning of reality is compensated by the numerous simulacra, 'such as the media which superficially and, in a highly artificial manner, serve the purpose of grounding meaning'. Buchanan (2010) expounds Baudrillad's argument is not that there is no reality anymore; it is rather that there is nothing can guarantee the meaning, a phenomenon that is largely known as postmodernism.

However, for the purpose of this essay what is at stake here is how to unearth a reality obscured and lost in the world of images when there is no guarantee of a meaning of such reality. But, at the same time if nothing can guarantee the meaning of reality then, all the same, it reaffirms both the image and narration's incapacity and inadequacy, singularly or in collaboration with, to represent any meaning out of reality. Furthermore, if the meaning-shaping power of reality is superseded by simulacra and images then it implies a certain transitional point or period when it occurs. Say, the period is when the image has become the ultimate commodity and when the society turns itself from a consumer society to a society of the spectacle whereby 'having' is replaced by 'appearing' as Debord ((2009) posits. Henceforth, looking back into the historical transition, when the social relations of productions have been obfuscated by the abstraction of commodity and images, may shed some light in this regard. To do so, it is necessary to bear in mind and acknowledge the inadequacy of both the mediums, photography and literature, while addressing effectively the problems arise by the somewhat equivalent status of image and reality through such practise.

Now that, an effective attempt to put a 'revolutionary use value' to photography is evident in the Fish Story (1995) by Alan Sekula, photographer and critic. Interestingly, he uses a documentary format of photographic representation and caption in a manner of scientific precision along with a historical narrative at a time when their credibility is in question in the age of postmodernism as Baudrilard's study of Simulacra suggests ${ }^{\text {ii }}$. Employing a documentary form, a kind of realistic representation of the subjects, he shows something which is always already abstract and hence cannot be represented, namely the abstract mode of capitalist economic system. Now, in opposition to an abstraction of the reality of the production and exploitation that cannot be represented through photography, as the images of the containers and cargo ships in Fish Story (1995) evince, he poses a reality that is lost, out of sight but still goes on in the deep ocean. In other words, he puts the image and language in a dialectical way, while showing the inadequacy of both the narrative forms, to adequately bring into the fore the 
historical and material realities and truth of capitalism. While doing so, he unfailingly proves that while everyone tends to think capitalis $m$ and globalisation is all about cyberspace and acceleration of communications, it is still heavily dependent on the concrete material reality of shipments and containers.

Sekula (1995) narrates the historical transformation of sea showing how from a place of prolific physiognomic contacts it has become a fluid world of wealth, without workers, shaped and boxed in the containers of the cargo ships, as a process started in 1956 and became ubiquitous in 1970s ( p133-134). He points out to a historical transformation when the complete abstraction of labour and production takes place in the sea through the containerization of products. While looking at the images of the containers in his photo-essay book one realizes the sheer size of the containers resist any representation. They resist the representation of the human labour, along exploitation, impoverishment that goes behind the production and distribution of each and every commodity boxed inside the giant containers. Thus, the containers abstract and obfuscate the invisible labour, and the images of the containers actually stands for a trace of a multi-layers of abstraction of human labour and poverty. Henceforth, Sekula's documentary representation actually shows that beneath the abstraction there is the presence of invisible labour and it makes the viewer reflect on and think over.

Sekula's representation is known as critical realism, "a way of seeking to understand the social reality by critically 'making notes' of it" (Baetens \& Gelder, 2010, p6). Elsewhere in the book Sekula accounts briefly the picture of cheap labours from Asian and Lat in A merican countries in the sea by the American ship-owners (Sekula, 1995, p74). The traces of the works of their labour in the sea, along with the labours of the lands, has been abstracted in the commodity they produce, and then, they have been doubly abstracted in the large containers of the cargo-ships. Sekula's photo-textual representation "as scratches of reality... leave their traces in our minds. They encourage, yes, even force reflection, and through that, slow changes can probably become a reality, certainly at the level of the individual" (Baetens \& Gelder, 2010, p6). Showing the sheer abstraction of the labour Sekula's narrative suggests a reality concealed from the vision, and unfailingly produces critical meaning and understanding, giving access to the social reality from the hindsight.

The photographic representations of the containers are nonetheless expressed with their 'phantom-like objectivity'. This is a kind of objectivity and abstraction that turn the human existence in the sea as redundant as perceived through Secula's (1995) representation. In this sense, he does the revolutionary work to transform the documentary technique, conventionally that used to add 'only a little to the critical understanding of the social world (Sekula, 1978, p236)' as he writes elsewhere, to something else and more towards a better understanding of the world. The paramount importance of his work could be perceived through the context where he works out for the sake of a revolutionary use value as Roberts (2012) argues that, "Fish Story expresses a shift from a culture of postmodernis $m$ to one of globalis $m$ and reflects the artist's effort to renew realist art in the wake of the postmodern culture of the 1980s." The photographic images of the containers and the sea bereft of human presence stand as the traces of the removal of the real condition of production in the photographic representation partially retrieved in Sekula's practise of critical realis $m$. He writes, this truth is legible only through Marx's notion of dead labour embedded in commodities (Sekula, 1995, p137). This implicitly suggests, if granted, that although in the age of simulacra there is no guarantee of meaning of the reality, looking back to history may still provide deeper understandings and insights.

Now it might be safely asserted that his work exactly does what he argues of art to be as he writes, 'I am arguing [...] for an art that documents monopoly capitalis m's inability to deliver the conditions of a fully human life (Sekula, 1978, p255) iii, and hence that implicitly calls for a fundamental change to the way things going on. In this regard, he goes with the same line of Benjamin's insistence to make photography something else by tearing it out from photographic clichés to the directions of alternatives. The significance of his work lies in the fact that he puts the revolutionary use value to photography in a time of the ubiquity and predominance of images over reality and a mistrust to revolution on a global scale, and that certainly has reopened some shut doors of possibilities.

\section{REFERENCES}

[1] Agee, J \& Evans, W. (1960) Let us Now Praise Famous Men: Three Tenant Families. Cambridge: The Riverside Press.

[2] Baetens, J. \& Gelder, H. (2010). "A Note on Critical Realis m Today” in Baetens, J. \& Gelder, H. (Eds.), Critical Realis m in Contemporary Art: Around Allan Sekula's Photography. Leuven: Leuven University.

[3] Bajorek, J. (2011), 'Holding Fast to Ruins: The A ir War in Brecht's Kriegsfibel,' in Broomberg, A and Chanarin,(eds). War Primer 2. London :Vale Studio. P125

[4] Baudrillard, J. (1994). Simulacra and simulation. Ann Arbor: University of Michigan Press. 
[5] Benjamin, W. (1970). 'The Author as Producer' in New Left Review, (July-August,1970).retrievedfro mhttp://newleftrevie w.org/?page $=$ article $\& v i e w=135$.

[6] Brecht, B. (1998) War primer. London: Libris.

[7] Buchanan, I. (2010). 'Jean Baudrillad' in $A$ Dictionary of Critical Theory. New York: Oxford University Press.

[8] Buchloh, B. (1995)'A llan Sekula:Photography Between Discourse and Document', in Sekula, A. (1995) Fish Story. Düsseldorf: Richter Verlag.

[9] Debord, G. (2009) Society of the Spectacle. Eastbourne: Soul Bay Press.

[10] Long. J. (2008). Paratextual Profusion: Photography and Text in Bertolt Brecht's War Primer in Poetics Today, March 2008.

[11] Marx, K. (1867) 'The Commodity' in Marx, K. Capital, Volume 1. (1867). Retrieved from www.marxists.org.

[12] Roberts, B. (2012). "Production in View: Allan Sekula's Fish Story and the Thawing of Postmodernism" in Tate Papers, no 18, Autumn 2012. Retrieved from https://www.tate.org.uk/research/publications/tate-pa pers/18/production-in-view-allan-sekulas-fish-storyand-the-thawing-of-postmodernism

[13] Rule, V. (2001). "Dispatches from the Dust Bowl" in The Guardian, Saturday 18 August, 2001.

[14] Scranton, R. (2017). "The Shipwreck of History: Bertolt Brecht's War Primer" in Los Angeles Review, June 4, 2017. Retrieved from https://lareviewofbooks.org/article/the-shipwreck-of -history-bertolt-brechts-war-primer/\#!

[15] Sekula, A. (1995) Fish Story. Düsseldorf: Richter Verlag.

[16] Sekula, A. (1978). 'Dis mantling Modernism, Reinventing Documentary' in The Massachusetts Review, Vol. 19, No. 4, Winter, 1978, retrieved from https://www.jstor.org/stable/i25088892.

[17] Simme1, G. (1903) 'The Metropolis and Mental Life', retrieved from

http://www.blackwellpublishing.com/content/bpl im ages/content store/sample chapter/0631225137/brid ge.pdf

[18] Sontag, S. (2005). On Photography. New York: Rosetta Books.

End Notes

i For a good discussion of the representational prohibition of the production process see-Benjamin Buchloh, 'Allan Sekula: Photography Between Discourse and Document', in Fish Story of Allan Sekula,(Düsseldorf: Richter Verlag, 1995).

ii See Bucloh, 'Sekula,' p190. He writes, '...his work programmatically redeploys precisely those subjects and semiotic and textual conventions that have been disqualified within modernism by longstanding interdictions: documentary pho tography, historical narrative.' 